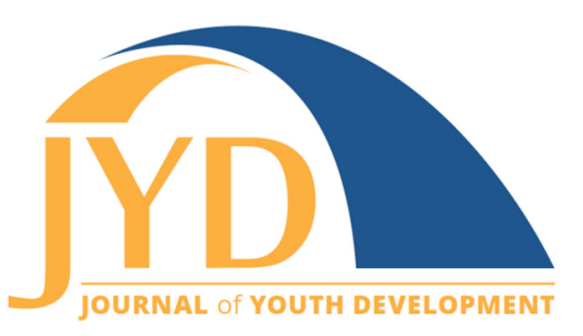

http://jyd. pitt. edu/ | Vol. 13 Issue 4 DOI 10.5195/jyd.2018.601 | ISSN 2325-4017 (online)

\title{
Exploring Purpose as a Resource for Promoting Youth Program Engagement
}

\author{
Anthony L. Burrow \\ Department of Human Development, Cornell University \\ alb325@cornell.edu \\ Jennifer P. Agans \\ Department of Recreation, Park, and Tourism Management; The Pennsy/vania State University \\ jennifer.agans@psu.edu
}

\section{Nicolette Rainone}

Baruch College and The Graduate Center, City University of New York nrainone@gradcenter.cuny.edu

\begin{abstract}
Recent evidence that reflecting on one's purpose in life increases engagement with academic tasks inspires questions about whether purpose interventions might enhance learning engagement more broadly. This potential may be particularly fruitful for programs serving youth from a wide range of ages wherein sustaining engagement may be challenging. Here, we explored whether a brief purpose writing intervention would increase adolescents' engagement in 4-H programs. Participants $(\mathrm{N}=130)$ were randomly assigned to write about either their sense of purpose or a control topic prior to the first day of a program, and they reported their level of program engagement at the end of that day. Regression analysis showed participant age was negatively associated with program engagement. However, writing about purpose halted this age-related decline in engagement. These preliminary findings situate purpose as a resource that can be leveraged to sustain older youths' interest and engagement in youth programming.
\end{abstract}

Key words: purpose, 4-H, positive youth development, program engagement, intervention

(cc) EY New articles in this journal are licensed under a Creative Commons Attribution 4.0 License. This journal is published by the University Library System, University of Pittsburgh and is cosponsored by the University of Pittsburgh Press. The Journal of Youth Development is the official peer-reviewed publication of the National Association of Extension 4-H Agents and the National AfterSchool Association. 
Purpose as a Resource

\section{Introduction}

Youth programs serve as important developmental contexts (Scales, Benson, Leffert, \& Blyth, 2000), providing spaces for young people to develop life skills while learning new things or pursuing their interests (Mahoney, Vandell, Simpkins, \& Zarrett, 2009; Simpkins, Ripke, Huston, \& Eccles, 2005). Indeed, many parents recognize the opportunities afforded by such programs, spending an estimated $\$ 113$ each week for children's after-school programs alone (Afterschool Alliance, 2014). With few exceptions (for a discussion see Roth, Malone, \& Brooks-Gunn, 2010), there is growing evidence that the return on this investment is favorable. Studies indicate that participating in out-of-school time (OST) programs is linked with a host of positive outcomes for youth, including greater academic performance and adjustment (Durlak, Weissberg, \& Pachan, 2010), more positive self-perceptions (Roffman, Pagano, \& Hirsch, 2001), and improved social behavior (Garst, Scheider, \& Baker, 2001). An important caveat to these findings, however, is that in order to fully capitalize on the benefits of programs, youth must feel actively and meaningfully engaged in them (Fredricks, 2011). Thus, identifying factors that contribute to youths' level of engagement, and that might be leveraged to maximize and sustain it over time, remains an important target for study.

Further complicating this issue, many OST programs deliver a diverse array of activities that often involve youth of many ages participating together, with the unfortunate reality that participation in such programs tends to decline as youth get older (Weiss, Little, \& Bouffard, 2005). Yet, because OST program participation can be immensely valuable to youth (Mahoney et al., 2009), it is important to investigate strategies for effectively capturing the attention and sustaining engagement of older youth. Based on longstanding evidence that adolescence is a period of the lifespan characterized by active identity exploration and goal development (Erikson, 1968; Luyckx \& Robitscheck, 2014; Marcia, 1993), we tested whether reflecting on one's sense of purpose in life would increase adolescent engagement with program learning. The purpose of this paper is to offer preliminary insight into whether this brief, youth-focused, and free intervention is amenable to and potentially effective within the context of 4-H youth development programs, and as a template for other OST programs as well. We aim to provide sufficient detail regarding the implementation of this intervention and its results to guide future testing. 
Purpose as a Resource

\section{Youth Engagement in Out-of-School Time Programs}

As researchers and practitioners well know, not all youth are equally engaged in the activities in which they participate. Thus, these stakeholders are beginning to identify more nuanced ways of assessing program engagement that go deeper than documenting attendance or simple participation (Bohnert, Fredricks, \& Randall, 2010). Compared to measures of program exposure or dosage, which quantitatively examine intensity or duration of participation, program engagement is thought to depict a more qualitative aspect of participation, focusing on youth experiences (Dawes \& Larson, 2011; Mahoney et al., 2009). This research has resulted in an understanding of engagement as encompassing three components: behavioral engagement (effort, attendance, rule-following), emotional engagement (interest, enjoyment, feelings of belonging), and cognitive engagement (self-regulation, goal pursuit, perceiving value in the activity), which work together to produce overall engagement (at high levels of each) or apathy and boredom (at low levels of each) (Bartko, 2005; Bohnert et al., 2010; Fredricks, Blumenfeld, \& Paris, 2004).

Compared to completing school assignments or homework, OST activities tend to be more engaging, with youth reporting higher levels of intrinsic motivation and concentration (Larson, 2000; Shernoff \& Vandell, 2007). This engagement may be related to youth program outcomes above and beyond quantitative measures of participation, such as attendance (Bohnert et al., 2010; Fredricks, Bohnert, \& Burdette, 2014; McGuire \& Gamble, 2006). To the extent that engagement is shown to be responsive to program characteristics, such as relationships with staff and peers, and program structure (i.e., opportunities for skill building and autonomy; Fredricks et al., 2014), it remains important to develop interventions that directly and beneficially influence youth engagement in programs.

\section{Purpose in Life}

One asset that may be useful for increasing program engagement is having a sense of purpose in life. Purpose can be defined as "a stable and generalized intention to accomplish something that is at once meaningful to the self and of consequence to the world beyond the self" (Damon, Menon, \& Bronk, 2003, p. 121). A rapidly growing body of work suggests that individuals begin to construct a sense of purpose during adolescence as identity and aspirations develop (Hill, Burrow, O'Dell, \& Thornton, 2010; Hill \& Burrow, 2012), and that doing so contributes to greater life satisfaction, positive mood, personal agency, and civic engagement (Bronk, Hill, Lapsley, Talib, \& Finch, 2009; Burrow \& Hill, 2011; Burrow, O'Dell, \& Hill, 2010; Malin, Ballard, \& Damon, 2015). 
Beyond its benefits to well-being in general, having a sense of purpose has also been shown to be advantageous within the specific context of youth programs. For example, Dawes and Larson (2011) found that making activities relevant to youths' sense of self, purpose, and learning for the future, helped young people to become psychologically engaged in programs. In addition, youth who find meaning in their participation in youth programs show more positive youth development outcomes (Bundick, 2011). In this way, a sense of purpose appears to provide youth who cultivate it with a platform for considering how information, activities, and experiences might be more significant and actionable, and thus helps them reap the benefits of youth program participation. Worth noting, however, purpose development may require more advanced cognitive capacities that emerge during middle and late adolescence (Burrow, Hill, Ratner, \& Sumner, 2018). Thus, it may be easier for older youth to consider and report on their sense of purpose than it is for younger youth.

Furthermore, although purpose is often examined as a dispositional attribute that someone either has or has not developed (e.g., Damon, 2008; Damon et al., 2003), there are recent demonstrations of purpose being experimentally primed or made salient. As a prominent example with particular relevance to the current study, Yeager and colleagues (2014) observed positive results for youth who took part in an intervention that asked them to briefly consider how they wanted to make the world a better place (self-transcendent purpose). Specifically, they found that writing about a self-transcendent purpose helped adolescents to engage more deeply with "boring" math problems, leading to greater persistence in solving them (Yeager et al., 2014). These results show that engaging with one's sense of purpose in life through a brief writing intervention led to deeper learning, self-regulation, and, ultimately, more positive youth outcomes by facilitating the construal of the task as personally meaningful. Thus, although a sense of purpose in life is thought to develop over time, it is possible to experimentally activate this sense through, for example, writing interventions (for other examples see Burrow, Hill, \& Sumner, 2016; Paunesku et al., 2015). That these types of brief and personally accessible interventions have positive effects, regardless of whether youth have developed a full-fledged sense of purpose in life, conforms with emerging work on wise-interventions (Walton, 2014) and makes them a potentially useful tool for helping young people engage in, and benefit from, OST programs. 
Purpose as a Resource

\section{The Present Study}

In light of prior research on the links between purpose and program engagement, as well as evidence that purpose interventions can be effective in academic learning environments (Yeager et al., 2014), we conducted an exploratory study of whether writing about one's sense of purpose in life could increase participant engagement in 4-H youth development programs. Guided by the findings considered above, we predicted that youth who are provided with an opportunity to write about their purpose would report greater engagement in these programs when compared to youth who did not have this opportunity.

We selected 4-H youth development programs as an ideal context to test this intervention, as 4-H is the largest youth development program in the United States, serving over 6 million youth annually, and providing a diverse array of programs in rural, suburban, and urban areas (4H.org, n.d.). As described below, we deliberately sampled youth from a wide variety of 4-H programs in different contexts (e.g., summer camp, after-school, community clubs) and with different types of activities (e.g., cooking, arts and crafts, animal care, science and engineering, etc.) to enhance the generalizability of our findings. Importantly, our analyses include youth spanning age ranges across adolescence. Because older youth may be more likely to have considered their sense of purpose in life, we expected the effect of our intervention to be more pronounced among them than among younger youth.

\section{Methods}

\section{Setting and Participants}

Participants were 161 youth (60\% female) between the ages of 10 and $18\left(M_{\text {age }}=13.38, S D=\right.$ 1.97) recruited from 22 4-H programs throughout New York State. Participants were $70.8 \%$ Caucasian/White, 10.6\% Hispanic/Latino, 7.5\% African American, 6.8\% Asian American, 3.7\% Native American, and $16.8 \%$ other. The percentages of participants from each racial/ethnic group exceed $100 \%$ because participants were able to select more than one racial/ethnic group. Since this study aimed to assess whether a purpose-priming activity enhances youth engagement with 4-H programming, researchers visited on the first day of programs to reduce the impact that prior program exposure might have on intervention effectiveness. Respondents were only included in analyses if they completed all items (writing activity, age, gender, and engagement items), which resulted in a final sample of 130 respondents. 


\section{Measures}

All participants completed a demographics form including their age, gender, and the name of the program they were attending.

\section{Program Engagement}

Engagement was assessed with the psychological engagement scale comprised of three components: cognitive ( $\alpha=.72$; i.e., "I really focus on an activity when I am doing it"), affective ( $\alpha=.79$; i.e., "I enjoy this activity and have fun when I am involved"), and purposeful ( $\alpha=.83$; i.e., "This activity helps give my life meaning and purpose") developed by Ramey et al. (2015). Given the substantial degree of overlap between the different facets of engagement accessed (correlations ranged from .67 to .79), a composite engagement scale was created by averaging across the three components. Cronbach's alpha for this composite was 0.91 .

\section{Procedure}

All youth enrolled in the 4-H programs that the research team visited were offered the opportunity to participate in the study (parental consent was collected by program staff before the visit). Prior to the start of the 4-H program activity, youth were asked to complete a paper and pencil writing exercise in which they were randomly assigned to either the control prompt (i.e., the most recent movie they saw) or the intervention prompt (i.e., purpose in life). Youth in the intervention group $(n=63)$ responded to the following two prompts, which were adapted from prior studies utilizing brief reflections on purpose and life aims (Bundick, 2011; Burrow et al., 2016), as well as research on self-transcendent intentions (Yeager et al., 2014): ${ }^{1}$

1. Please tell us about your purpose in life. What is it that you most want to accomplish or contribute? Even if you do not feel that you have a specific purpose now, consider what it might be in the future.

2. How will working toward your purpose help other people or help the world?

\footnotetext{
${ }^{1}$ When this study was initially launched, the two questions within each prompt were combined into one broader question to be consistent with previous administrations of this type of intervention with emerging adults (i.e., Burrow et al., 2016). However, based on early interactions with our youth participants, we modified this protocol by separating these questions into two distinct parts to provide greater clarity and ease of interpretation.
} 
Purpose as a Resource

Participants in the control condition $(n=67)$ responded to the following two prompts:

1. Please tell us about the last movie that you've seen. What was the title? What was it about?

2. What was your favorite or least favorite part of the movie?

After completing the writing exercise, youth were asked to complete a short survey assessing demographic information and two constructs (i.e., affect and Big 5 personality) not included in the present analyses. Subsequent to the completion of these measures, the program began. When the program ended (typically one to three hours later), youth were asked to complete a final survey assessing their level of engagement with the program material.

\section{Results}

\section{Preliminary Analyses}

There was no significant difference between the two conditions with respect to the total number of words written in response to the prompts (control: $M=61.34, S D=36.64$; purpose: $M=$ $57.05, S D=23.92), t(114.34)=.80, p=.43$. Additionally, no significant difference was observed between the two conditions with respect to the age of participants (control: $M=$ $13.51, S D=2.03$; purpose: $M=13.49, S D=1.96), t(128)=.55, p=.97)$. However, age was positively correlated with the total number of words written in response to either prompt overall, $r(128)=.17, p=.05$. Across all participants, engagement was slightly above the scale midpoint $(M=3.66, S D=.87)$.

\section{Main Hypotheses}

To explore whether age, writing condition, or their interaction predicted levels of program engagement, an OLS multivariate regression was conducted. In this analysis, the composite engagement variable was regressed on participant gender, age, total number of words written, writing condition (i.e., control prompt or intervention prompt), and the interaction between writing condition and age (see Table 1). Combined, these predictors explained a significant amount of the variance in engagement ( $9 \%$ of total variance), $f(5,124)=2.69, p=.024$. While a significant main effect emerged for age, $b=-.32, S E=.10, p=.003$, this was qualified by a significant interaction with writing condition, $b=.33$, SE $=.15, p=.030$. To inspect the 
Purpose as a Resource

nature of this interaction, slopes for both conditions were plotted at both 1 standard deviation below and above the mean for age. As shown in Figure 1, simple slopes analyses revealed that, while age was negatively associated with engagement for those in the control condition, $b=-$ $13, S E=.05, p=.014$, it was unrelated to engagement for those who wrote about purpose, $b$ $=.03, S E=.06, p=.543$. Thus, consistent with our prediction, writing about purpose served as a resource, though primarily for older youth. That is, engaging with one's purpose prevented the age-related decline in engagement that would have otherwise been observed in the programs.

Table 1. Hierarchical Regression Estimates Predicting Program Engagement.

\begin{tabular}{|l|c|c|c|c|c|}
\hline Predictors & $\boldsymbol{B}$ & SE B & $\boldsymbol{\beta}$ & $\begin{array}{c}95 \% \boldsymbol{C I} \\
\text { Lower }\end{array}$ & $\begin{array}{c}95 \% \boldsymbol{C I} \\
\text { Upper }\end{array}$ \\
\hline Gender & -.24 & .17 & -.13 & -.57 & .10 \\
\hline Age & $-.32 * *$ & .10 & -.36 & -.52 & -.11 \\
\hline Total words written & .00 & .00 & .10 & .00 & .01 \\
\hline Writing condition & -.01 & .15 & -.01 & -.29 & .31 \\
\hline Age X Writing Condition & $.33 *$ & .15 & .26 & .03 & .62 \\
\hline
\end{tabular}

Notes. Model test: $\Re(5,124)=2.69, p<.05 . R^{2}=.098$. Gender: male $=1$ female $=0$.

Writing condition: $0=$ control, $1=$ purpose. $* p<.05$. $* * p<.01$.

Figure 1. Interaction Between Age and Writing Condition Predicting Program Engagement.

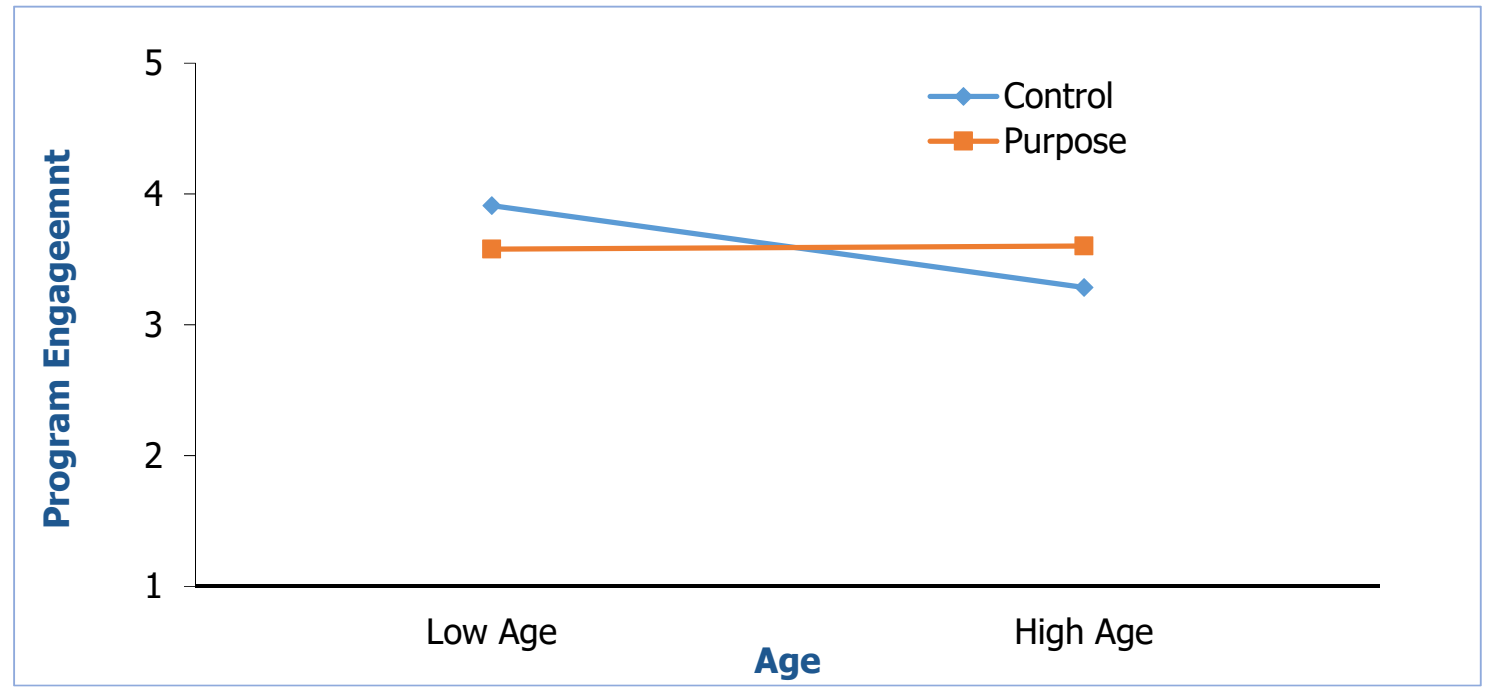

Note. Low = $1 S D$ below the mean. High = $1 S D$ above the mean. 
Purpose as a Resource

\section{Discussion}

The benefits of youth programs can be more fully actualized when participants are fully engaged with the content being delivered. Among adolescents participating in a variety of 4-H programs delivered in New York State, we found that levels of youth engagement generally declined with age. The results of our exploratory study suggest that these programs, which often serve youth of a wide variety of ages at the same time, may not provide environmental affordances that match the developmental needs of older youth (Eccles et al., 1993). However, this trend of less engagement among older youth was attenuated for those who wrote about their sense of purpose in life just prior to beginning their program. These results are consistent with past work suggesting that even brief opportunities to consider one's purpose can provide young people with a personally-relevant and motivational context for engaging with new information (Yeager et al., 2014). Moreover, these findings extend evidence that purpose supports engagement beyond traditional academic settings and works similarly in activities carried out in a variety of OST program types. Against the backdrop of the substantial monetary and personnel resources invested in the delivery of 4-H and other OST programs to youth spanning a wide range of ages, evidence that a no-cost and brief writing task proved beneficial to levels of youth engagement is particularly promising and sets a course for future testing and implementation.

We highlight three broad conclusions that can be drawn from this study and interpret them in the context of existing work and areas of emerging interest on youth engagement and program delivery. First, while some readers may be tempted to conclude that writing about purpose boosted levels of engagement, our results instead suggest that writing about purpose attenuated the decline in engagement (illustrated by our control group) expected among older youth (Weiss et al., 2005). Though nuanced, this point is important as it suggests that our brief experimental manipulation did not reverse a common normative pattern, but instead halted the trend, potentially leaving youth better able to attend to and appreciate program content. Future research might seek to determine if simply staving off expected declines in engagement sufficiently impacts downstream outcomes or if increasing engagement levels is necessary. Although Dawes and Larson (2011) observed such increases in engagement naturally occurring for a subset of youth who felt that program content was relevant to their purpose in life, it remains to be determined what combination of program characteristics and individual factors (Eccles et al., 1993) could consistently produce increased engagement for all youth. 
Purpose as a Resource

Second, youth in the purpose condition in this study were not instructed to explicitly describe connections between program content and their own purpose. Thus, as observed in academic settings (Yeager et al., 2014), the substance of one's own purpose need not be tethered to the material being presented in order for this intervention to maintain youths' engagement in programs. That said, future studies should examine whether there is any additional benefit to engagement if youth are asked to explicitly describe perceived connections between their own purpose and program contents. Furthermore, if collected prior to a program's initiation, program leaders and educators could utilize youths' articulations of their own purpose to curate a more person-centered and thus potentially interesting program. This general principle of designing OST learning opportunities such that youth are actively engaged in their own learning is central to positive youth development (Mahoney, Larson, \& Eccles, 2005) and to the handson, youth-centered approach taken in 4-H programs (4-H.org, n.d.). However, many existing programs may have little capacity to tailor several different programs for youth of different ages, and so future work will need to explore strategies for doing this without alienating subsets of youth whose aspirations differ substantially.

Third, the benefits of writing about purpose were not evident among the youngest youth in our study. Articulating one's purpose may be a more difficult task for youth who have not yet grappled with questions of identity and aspirations (Hill \& Burrow, 2012; Hill, Burrow, \& Sumner, 2013). Longstanding developmental literature suggests that these explorations may not begin in earnest until middle adolescence, and continue through emerging adulthood (Erickson, 1968). While our sample size precludes more precise estimation of specific age boundaries, our writing task may be ineffective prior to middle adolescence. This may not be problematic for programs designed for children and early adolescents who may naturally find them more engaging (such as many 4-H programs). Yet for older youth, as illustrated in our results, a purpose intervention such as ours might be particularly beneficial insofar that it might align with the developmental stage and needs of the youth for whom it is intended (Eccles et al., 1993).

\section{Limitations and Conclusion}

It is our hope that noting some of the limitations of this study will be instructive for future research. First, while we have emphasized brevity as an important feature of our purpose writing task, it is unclear if the effects demonstrated would have been greater if youth were given more time to provide their response, or scaffolding was made available (perhaps via adult assistance or peer discussion) to help youth think about their purpose more deeply. It is 
Purpose as a Resource

reasonable to expect that the more fully youth have considered their purpose, the more connections between it and program content they would perceive, potentially elevating engagement. Should it prove fruitful to do so, subsequent work might examine how to help youth explicitly connect program content with their purpose. Additionally, while this study has provided an important contribution by revealing the impact that this brief writing intervention can have on participant engagement in 4-H youth development programs, this study did not examine the mechanisms that other researchers (e.g. Yeager et al., 2014) have identified to explain the benefits of purpose for youth outcomes. Since our findings demonstrate the applicability of this activity for OST programs, we suggest that future researchers test the mechanisms by which purpose acts as a resource to promote youth program engagement.

Future studies might also explore the longer-term implications of purpose writing on program engagement as we acknowledge that the temporal design of this study is limited to a single day, and, therefore, it is unclear how long the observed effect persists. We restricted our measurement of engagement to one program session because this was thought to provide the richest view into the impact of the intervention. However, many programs are multifaceted and expose youth to a diverse array of activities, speakers, or immersion experiences over the course of multiple sessions. Nevertheless, conceptually similar work has noted that short-term interventions might lead to more long-lasting effects through small adjustments in the way that youth construe tasks (Yeager et al., 2014). Through the realization that program content can be connected to one's sense of purpose in life, this brief writing intervention may lead to sustained program engagement. However, questions remain as to whether a single dosage of writing would be sufficient to influence engagement across multiple days or weeks, or whether repeating the task would renew its influence. For longer-term programs such as 4-H clubs or after-school programs, providing activities in which youth repeatedly think about their purpose (via writing intervention) may facilitate deeper engagement over the course of the program.

Finally, due to sample size limitations, we could not explore whether writing about purpose was more beneficial to youth in certain types of programs. The variety of programs offered by 4-H provides an excellent opportunity to delineate when and where reflecting on one's aspirations may truly open youth to new experiences and learning opportunities. Several program characteristics might significantly influence the effects found here, including whether the program allows for self-reflection, like record-book keeping or working on one's project for county fairs, or instead aims to expose youth to new opportunities such as STEM or servicelearning (i.e., creating conditions similar to those observed by Dawes \& Larson, 2011, or providing unique developmental affordances; Eccles et al., 1993). Ultimately, situating our 
Purpose as a Resource

understanding of program engagement at the crossroads of program characteristics and internal characteristics will allow for greater clarity regarding what optimizes youth experiences and outcomes. Based on the findings presented here, purpose in life should be considered a valuable resource for enhancing the impact of OST programs.

\section{Acknowledgements}

Data collection for this study was facilitated by the Program for Research on Youth Development and Engagement (PRYDE) at Cornell University, funded by a gift from Rebecca Q. Morgan. PRYDE links research faculty with 4-H staff and programs throughout New York State to promote innovative intervention studies that solve problems affecting youth. Thus, we are thankful for PRYDE enabling us to identify programs representative of 4-H offerings, more easily coordinate data collection opportunities, and disseminate study results to the specific programs that participated throughout the state.

\section{References}

Afterschool Alliance. (2014). America after 3PM: Afterschool programs in demand. Washington, DC: Author.

Bartko, W. T. (2005). The ABCs of engagement in out-of-school time programs. New Directions for Student Leadership, 2005(105), 109-120.

Bohnert, A., Fredricks, J., \& Randall, E. (2010). Capturing unique dimensions of youth organized activity involvement: Theoretical and methodological considerations. Review of Educational Research, 80(4), 576-610. doi:10.3102/0034654310364533

Bronk, K. C., Hill, P. L., Lapsley, D. K., Talib, T. L., \& Finch, H. (2009). Purpose, hope, and life satisfaction in three age groups. The Journal of Positive Psychology, 4(6), 500-510. doi:10.1080/17439760903271439

Bundick, M. J. (2011). Extracurricular activities, positive youth development, and the role of meaningfulness of engagement. The Journal of Positive Psychology, 6(1), 57-74.

Burrow, A. L., \& Hill, P. L. (2011). Purpose as a form of identity capital for positive youth adjustment. Developmental Psychology, 474), 1196-1206. doi:10.1037/a0023818

Burrow, A. L., Hill, P. L., Ratner, K., \& Sumner, R. (2018). A better tomorrow: Toward a stronger science of youth purpose. Research in Human Development, 15(2), 167-180. doi:10.1080/15427609.2018.1445926

Burrow, A. L., Hill, P. L., \& Sumner, R. (2016). Leveling mountains: Purpose attenuates links between perceptions of effort and steepness. Personality and Social Psychology Bulletin, 42, 94-103. 
Purpose as a Resource

Burrow, A. L., O'Dell, A. C., \& Hill, P. L. (2010). Profiles of a developmental asset: Youth purpose as a context for hope and well-being. Journal of Youth and Adolescence, 39(11), 1265-1273.

Damon, W. (2008). The path to purpose. New York, NY: Free Press.

Damon, W., Menon, J., \& Bronk, K. C. (2003). The development of purpose during adolescence. Applied Developmental Science, 73 ), 119-128.

Dawes, N. P., \& Larson, R. (2011). How youth get engaged: Grounded-theory research on motivational development in organized youth programs. Developmental Psychology, 471), 259-269.

Durlak, J. A., Weissberg, R. P., \& Pachan, M. (2010). A meta-analysis of after-school programs that seek to promote personal and social skills in children and adolescents. American Journal of Community Psychology, 45(3-4), 294-309.

Eccles, J. S., Midgley, C., Wigfield, A., Buchanan, C. M., Reuman, D., Flanagan, C., \& Mac Iver, D. (1993). Development during adolescence: The impact of stage-environment fit on young adolescents' experiences in schools and in families. American Psychologist, 48(2), 90-101. doi:10.1037/0003066X.48.2.90

Erikson, E. H. (1968). Identity: Youth and crisis. New York, NY: Norton.

4-H.org (n.d.). About 4-H. Retrieved from http://4-h.org/

Fredricks, J. A. (2011). Engagement in school and out-of-school contexts: A multidimensional view of engagement. Theory Into Practice, 50(4), 327-335.

Fredricks, J. A., Blumenfeld, P. C., \& Paris, A. H. (2004). School engagement: Potential of the concept, state of the evidence. Review of Educational Research, 74(1), 59-109.

Fredricks, J. A., Bohnert, A. M., \& Burdette, K. (2014). Moving beyond attendance: Lessons learned from assessing engagement in afterschool contexts. New Directions for Student Leadership, 2014(144), 45-58. doi:10.1002/yd.20112

Garst, B., Scheider, I., \& Baker, D. (2001). Outdoor adventure program participation impacts on adolescent self-perception. Journal of Experiential Education, 24(1), 41-49. doi: $10.1177 / 105382590102400109$

Hill, P. L., \& Burrow, A. L. (2012). Viewing purpose through an Eriksonian lens. Identity: An International Journal of Theory and Research, 12(1), 74-91. doi:10.1080/15283488.2012.632394

Hill, P. L., Burrow, A. L., \& Sumner, R. (2013). Addressing important questions in the field of adolescent purpose. Child Development Perspectives, 74 ), 232-236.

Hill, P. L., Burrow, A. L., O'Dell, A. C., \& Thornton, M. A. (2010). Classifying adolescents' conceptions of purpose in life. The Journal of Positive Psychology, 5(6), 466-473. doi:10.1080/17439760.2010.534488

Larson, R. W. (2000). Toward a psychology of positive youth development. American Psychologist, 55(1), 170-183. 
Purpose as a Resource

Luyckx, K., \& Robitschek, C. (2014). Personal growth initiative and identity formation in adolescence through young adulthood: Mediating processes on the pathway to well-being. Journal of Adolescence, 377), 973-981. doi:10.1016/j.adolescence.2014.07.009

Mahoney, J. L., Larson, R. W., \& Eccles, J. S. (Eds.). (2005). Organized activities as contexts of development: Extracurricular activities, after-school and community programs. Mahwah, NJ: Lawrence Erlbaum Associates.

Mahoney, J., Vandell, D. L., Simpkins, S., \& Zarrett, N. (2009). Adolescent out-of-school activities. In R. M. Lerner \& L. Steinberg (Eds.), Handbook of adolescent psychology (3rd ed., pp. 228-269). Hoboken, NJ: Wiley.

Malin, H., Ballard, P. J., \& Damon, W. (2015). Civic purpose: An integrated construct for understanding civic development in adolescence. Human Development, 58(2), 103-130. doi:10.1159/000381655

Marcia J.E. (1993) The Ego Identity Status Approach to Ego Identity. In J. E. Marcia, A. S. Waterman, D. R. Matteson, \& S. L. Archer (Eds.), Ego identity (pp. 3 - 21). New York, NY: Springer.

McGuire, J. K., \& Gamble, W. C. (2006). Community service for youth: The value of psychological engagement over number of hours spent. Journal of Adolescence, 29(2), 289-298. doi:10.1016/j.adolescence.2005.07.006

Paunesku, D., Walton, G. M., Romero, C., Smith, E. N., Yeager, D. S., \& Dweck, C. S. (2015). Mind-set interventions are a scalable treatment for academic underachievement. Psychological Science, 26, 784-793. doi:10.1177/0956797615571017

Ramey, H. L., Rose-Krasnor, L., Busseri, M. A., Gadbois, S., Bowker, A., \& Findlay, L. (2015). Measuring psychological engagement in youth activity involvement. Journal of Adolescence, 45, 237-249. doi:10.1016/j.adolescence.2015.09.006

Roffman, J. G., Pagano, M. E., \& Hirsch, B. J. (2001). Youth functioning and experiences in inner-city after-school programs among age, gender, and race groups. Journal of Child and Family Studies, 10(1), 85-100. doi:10.1023/A:1016681517546

Roth, J. L., Malone, L. M., \& Brooks-Gunn, J. (2010). Does the amount of participation in afterschool programs relate to developmental outcomes? A review of the literature. American Journal of Community Psychology, 45(3-4), 310-324. doi:10.1007/s10464-010-9303-3

Scales, P. C., Benson, P. L., Leffert, N., \& Blyth, D. A. (2000). Contribution of developmental assets to the prediction of thriving among adolescents. Applied Developmental Science, 4(1), 27-46. doi:10.1207/S1532480XADS0401_3

Shernoff, D. J., \& Vandell, D. L. (2007). Engagement in after-school program activities: Quality of experience from the perspective of participants. Journal of Youth and Adolescence, 36(7), 891903. doi:10.1007/s10964-007-9183-5 
Purpose as a Resource

Simpkins, S. D., Ripke, M., Huston, A. C., \& Eccles, J. S. (2005). Predicting participation and outcomes in out-of-school activities: Similarities and differences across social ecologies. New Directions for Student Leadership, 2005(105), 51-69. doi:10.1002/yd.107

Walton, G. M. (2014). The new science of wise psychological interventions. Current Directions in Psychological Science, 23(1), 73-82. doi:10.1177/0963721413512856

Weiss, H. B., Little, P., \& Bouffard, S. M. (2005). More than just being there: Balancing the participation equation. New Directions for Student Leadership, 2005(105), 15-31.

Yeager, D. S., Henderson, M. D., Paunesku, D., Walton, G. M., D’Mello, S., Spitzer, B. J., \& Duckworth, A. L. (2014). Boring but important: A self-transcendent purpose for learning fosters academic selfregulation. Journal of Personality and Social Psychology, 1074), 559-580. doi:10.1037/a0037637 